\title{
IRRESPONSABILIDAD PATERNA Y CONSECUENCIAS SOCIALES
}

\author{
Graciela Esther Llanos Chávez*
}

\section{Resumen}

Padre, madre y niño forman una triada de desarrollo biopsico-social en constante movimiento, teniendo al Estado como ente garantizador de la convivencia social, siendo que éste actúa a través de sus diferentes instituciones cuando sea el padre o la madre quienes incumplen su obligación alimentaria respecto de sus hijos, deviniendo en irresponsabilidad paterna con imprevisibles consecuencias en la vida de los hijos, lo que podemos avizorar desde la perspectiva de un estudio realizado el año 2005.

Palabras clave: Responsabilidad e irresponsabilidad paterna - consecuencias sociales - pensión de alimentos.

\begin{abstract}
Father, Mother and child are a triad of biopic- social development in constant motion, having the State as an entity guarantor of social coexistence, acting this through different institutions when the parents don't fulfill their children needs, becoming in parental irresponsibility with unpredictable consequences in the kids life. Which can be seen in many studies made on 2005.
\end{abstract}

Key words: Parental responsibility and irresponsibility - social consequences - child support.

\section{Sumario}

1. Introducción. 2. La paternidad en el Perú. 3. La legislación sobre la paternidad en el Perú. 4. Una aproximación desde una perspectiva local al problema de la irresponsabilidad paterna. $\overline{5}$. Conclusiones.

* Juez Especializado Titular de la Corte Superior de Juslicia de Lima - Poder Judicial de Perú. 


\section{INTRODUCCIÓN}

Junto con el Estado, el padre y la madre de los menores de edad tienen la responsabilidad de apoyar su desarrollo bio-sicosocial y su incorporación paulatina a la sociedad. Sin embargo, muchos hombres evaden sus responsabilidades como padres, y en otros casos llegan a atentar contra los derechos y dignidad de sus hijos. En suma, los padres pueden contribuir a la reproducción de la pobreza cuando obstaculizan la incorporación a la sociedad y el desarrollo personal de sus hijos e hijas. ${ }^{1}$. La naturaleza del ser humano nos señala que los menores de edad necesitan amor, protección, alimento, salud, educación y capacitación para llegar a ser un ciudadano que participe en el desarrollo de la sociedad, y los hombres como padres tienen la responsabilidad de contribuir a la satisfacción de esas necesidades.

\section{LA PATERNIDAD EN EL PERÚ}

En el Perú es bastante común oír a las personas decir “No conozco a mi padre, mi mamá me ha criado sola" o "Mi papá no vive con nosotras y no nos ayuda en nada". La paternidad irresponsable -cuando el padre se desentiende, en parte o por completo, de la manutención, crianza y educación de sus hijos a menudo es considerado una conducta natural, porque "los hombres son asi". En realidad, la paternidad responsable es algo que aprendemos, algo construido a través de las costumbres, la educación y las leyes?2.

Por ello, la Constitución Política del Perú señala en el artículo $6^{\circ}$ que “La política nacional de población tiene como objetivo difundir y promover la paternidad y la maternidad responsables..."

\section{LA LEGISLACIÓN SOBRE LA PATERNIDAD EN EL PERÚ}

El artículo $93^{\circ}$ del Código de los Niños y Adolescentes establece que "Es obligación de los padres prestar alimentos a sus hijos.." siendo una de las principales garantías frente a la irresponsabilidad paterna la pensión alimenticia la cual es un derecho intangible del niño/niña y se establece como obligación del padre a proporcionar manutención y afecto para garantizar su desarrollo integral. Sin embargo, esto en el plano teórico aparece como un instrumento ideal en la defensa de los derechos del niño pero resulta que en la práctica casi no funciona. El mero hecho de tener que reclamar la pensión por vía judicial es aún un problema, pues, todo el peso recae sobre las mujeres que demandan la pensión y el Estado peruano aunque promueve la paternidad responsable no aplica medidas pertinentes para facilitar que la ley se cumpla. 
Por otro lado no existen políticas públicas específicas y eficaces para fomentar la responsabilidad paterna ${ }^{3}$.

Todo esto hace que los trámites sean engorrosos. Como resultado, muchas mujeres prefieren no reclamar la pensión porque creen que no vale la pena. Otras no la demandan porque piensan que la injerencia de un padre irresponsable es peor que su ausencia. También hay mujeres que no solicitan la pensión por orgullo, queriendo probar a su ex pareja que bien pueden criar a sus hijas o hijos ellas solas. Pero con estas actitudes sólo ayudan a promover la paternidad irresponsable. Negar alimentos a su prole es una forma de violencia familiar y los niños tienen derecho a vivir una vida digna sin violencia.

\section{UNA APROXIMACIÓN DESDE UNA PERSPECTIVA LOCAL AL PROBLEMA DE LA IRRESPONSABILIDAD PATERNA}

La irresponsabilidad paterna se viene reproduciendo en la realidad del Perú, pues desde mi observación participativa de la realidad social en la ciudad de Pucallpa ${ }^{4}$ soy consciente del rol defensor de los derechos del niño que nos corresponde asumir como operadores del derecho, de la sociedad en su conjunto, de la institución familiar y de los grupos más vulnerables de la población ${ }^{5}$.

El objetivo de la investigación que realice el año 2005, fue el de determinar "la relación entre la irresponsabilidad paterna y las consecuencias sociales en los niños en estudio del Juzgado de Familia de la Provincia de Coronel Portillo Ucayali 2005".

Se desarrolló metodológicamente un estudio descriptivo-explicativo; para cuyo efecto se entrevistó a 40 niños seleccionados aleatoriamente, quienes respondieron satisfactoriamente respecto a las consecuencias sociales de la irresponsabilidad paterna (incumplimiento de la pensión alimentaría). Del mismo modo se entrevistó a las madres de los niños en estudio para caracterizar la irresponsabilidad paterna y se utilizó una ficha documental para identificar los aspectos concernientes al proceso judicial en los expedientes de la demanda por alimentos.

Esta investigación dio como resultado que la irresponsabilidad paterna se expresa principalmente en el incumplimiento de la pensión de alimentos y produce consecuencias sociales desfavorables afectando la satisfacción de las necesidades básicas de los niños en estudio y alterando su bienestar. 
Así podemos observar lo siguiente, expresado en valores cuantitativos de medición:

Existe insatisfacción de las necesidades de alimentación determinando situación nutricional en riesgo y deficiente en los niños en estudio con $p=$ 0.015 .

Del mismo modo produce consecuencias desfavorables en las condiciones de la vivienda de los niños en estudio observándose viviendas insalubres y precarias con $p=0.039$. Seguidamente asumimos que también determina consecuencias desfavorables en la vestimenta de los niños, observándose vestimenta precaria y menesterosa con $p=0.000$.

Al contrastar la influencia en la educación escolarizada observamos consecuencias desfavorables expresado en retraso y fracaso educacional con $\mathrm{p}=0.015$.

También se observa consecuencias desfavorables en la salud, de los niños en estudio, presentando regular y mal estado de salud con $\mathrm{p}=0.008$.

Con respecto a la participación en espacios culturales de los niños en estudio observamos baja participación o en su defecto ausencia de un desarrollo cultural (retraso y ausencia) con $\mathrm{p}=0.001$.

Al contrastar la influencia de la irresponsabilidad paterna en la participación de los niños en estudio a espacios de recreación asumimos que existe limitada participación o ausencia a los mismos con $\mathrm{p}=0.004$.

Finalmente se asume que existe relación entre la irresponsabilidad paterna con las consecuencias sociales determinando trabajo infantil riesgoso y excesivo en los niños en estudio considerándose los resultados estadísticamente significativas con $\mathrm{p}=0.003$.

Por lo expuesto se observa que la irresponsabilidad paterna alcanza altas proporciones $(80 \%)$ en el contexto del estudio, lo que supedita un alto riesgo para las condiciones de desarrollo social del niño y limita el bienestar que se expresa en: alimentación en riesgo y deficitaria, viviendas insalubres, vestimentas menesterosas, retraso académico, regular y mal estado de salud, bajo desarrollo cultural y riesgoso y excesivo trabajo infantil. Los niños experimentan ciertos momentos de esparcimiento relativo a las actividades deportivas que no es suficiente para el pleno desarrollo infantil. 


\section{CONCLUSIONES}

1. El $80,0 \%$ de los demandados no cumplen con la pensión de alimentos y tan solo el $20,0 \%$ si cumplían con dicha pensión, ello indica que existe alta proporción de abandono en cuanto al cumplimiento de la pensión alimentaría.

2. El 57,5\% (23 niños demandantes) estaban en riesgo de alimentación, el $32,5 \%$ (13 niños demandantes) ya estaban en deficiencias alimentarías y solo el 10,0\% (4 niños demandantes) estaban en una adecuada alimentación.

3. El 52,5\% (21 niños demandantes) vivían en una vivienda insalubre, el $35,0 \%$ (14 niños demandantes) peor aún vivían en una vivienda precaria y solo el 12,5\% (5 niños demandantes) vivían en una vivienda adecuada.

4. En cuanto a la vestimenta, el 55,0\% (22 niños demandantes) tenían vestimentas menesterosa, el $15,0 \%$ ( 6 niños demandantes) peor aún vestían precariamente y el 30,0\% (12 niños demandantes) vestían adecuadamente.

5. El 60,0\% (24 niños demandantes) tenían un retraso académico, el 25,0\% (10 niños demandantes) peor aún habían fracasado en su educación y solo el $15,0 \%$ (6 niños demandantes) mantenían un desarrollo académico.

6. El $67,5 \%$ (27 niños demandantes) mantenían un regular estado de salud, ya el 22,5\% (9 niños demandantes) tenían mal estado de salud y solo el 10,0\% (4 niños demandantes) tenían buen estado de salud.

7. Con respecto al espacio cultural el $55,0 \%$ (22 niños demandantes) no tenían desarrollo cultural, el 32,5\% (13 niños demandantes) mantenían un retraso en el desarrollo cultural y solo el 12,5\% (5 niños demandantes) tenían desarrollo cultural.

8. El 47,5\% (19 niños demandantes) tenían suficiente esparcimiento, pero el $30,0 \%$ (12 niños demandantes) mantenían un limitado esparcimiento y solo el $22,5 \%$ ( 9 niños demandantes) no presentaban esparcimiento alguno.

9. Y, en cuanto al trabajo infantil el 55,6\% (10 niños demandantes) estaban en riesgo de trabajo, los otros $33,3 \%$ ( 6 niños demandantes) peor aún se dedicaban a un excesivo trabajo y solo el $11,1 \%$ ( 2 niños demandantes) se dedicaban a un trabajo adecuado. 
10. Cuando relacionamos la irresponsabilidad paterna expresada principalmente en el incumplimiento de la pensión de alimentos observamos que produce consecuencias desfavorables en la satisfacción de las necesidades de alimentación de los niños en estudio determinando situación nutricional en riesgo y deficiente con $\mathrm{p}=0.015$.

11. Del mismo modo asumimos que la irresponsabilidad paterna produce consecuencias desfavorables en las condiciones de la vivienda de los niños en estudio contando con viviendas insalubres y precarias el que fue contrastado a través de la prueba estadística CHI CUADRADA $(\mathrm{p}=0.039)$.

12. Al contrastar la influencia de la irresponsabilidad paterna con la dotación de vestimenta a los niños en estudio, asumimos que existe influencia desfavorable en la satisfacción de las necesidades de vestimenta (vestimenta precaria y menesterosa) $(p=0.000)$.

13. Al contrastar la influencia de la irresponsabilidad paterna con la educación escolarizada de los niños en estudio, asumimos que se establece consecuencias desfavorables expresado en retraso y fracaso educacional $(p=0.015)$.

14. También asumimos que la irresponsabilidad paterna influye en la presencia de consecuencias desfavorables en el estado de salud de los niños en estudio evidenciándose estado de salud regular y mal estado, el que fue contrastado a través de la prueba estadística CHI CUADRADA $(p=0.008)$.

15. Con respecto a la relación de la irresponsabilidad paterna con la baja participación de los niños en estudio en espacios culturales observamos efectos desfavorables expresados en ausencia de un desarrollo cultural (retraso y ausencia) considerándose los resultados estadísticamente significativos con $p$ $=0.001$.

16. Al contrastar la influencia de la irresponsabilidad paterna con la participación de los niños en estudio a espacios de recreación asumimos que existe influencia desfavorable en la satisfacción de las necesidades de recreación (limitado y ausencia) con $\mathrm{p}=0.004$.

17. Con respecto a la relación de la irresponsabilidad paterna con las consecuencias desfavorables en la generación del trabajo infantil de los niños en estudio observamos que los niños efectúan trabajo infantil que se caracteriza por ser riesgoso y excesivo considerándose los resultados estadísticamente significativas con $p=0.003$. 
18. En consecuencia afirmamos que la irresponsabilidad paterna influye de manera directa en la presencia de consecuencias sociales desfavorables para el desarrollo humano de los niños que experimentan dicha situación.

Acosta, F. Hogares con jefas mujeres y bienestar familiar en México. 1998. Pág. 64.

Schmuckler B. Familias y relaciones de género en transformación: cambios trascendentales en América Latina y El Caribe, México, Population Council/EDAMEX. 2000. Pág. 76.

3 Alatorre, J. y L. C. Atkin. El embarazo adolescente y la pobreza. 1998. Pág. 34.

4 Mediante Resolución Administrativa No 082-2008-CE-PJ publicada el 24 de mayo de 2008, fui trasladada del Distrito Judicial de Ucayali al Distrito Judicial de Lima.

5 Bonfil P. y Salles V. Mujeres pobres: salud y trabajo. México: GIMTRAP, 2002. Pág. 57. 